\title{
HUBUNGAN RELIGIUSITAS DENGAN KESEJAHTERAAN PSIKOLOGIS PADA PASIEN DIABETES MELITUS DI KLINIK HUSADA KIMIA FARMA SARIO MANADO
}

\author{
Hendro Bidjuni \\ Vandri Kallo \\ Program Studi Ilmu Keperawatan Fakultas Kedokteran \\ Universitas Sam Ratulangi Manado \\ Email : bidjunihdro@yahoo.co.id
}

\begin{abstract}
Psychological Well-being is a full achievement of one's psychological potential and a situation when individuals can accept their own strengths and weaknesses as they are, have life goals, develop positive relationships with others, become independent individuals, able to control the environment, and continue to grow personally. The Purpose of this study was to find out whether there was a correlation between religiosity and psychological well-being in patients with diabetes mellitus at the Husada Kimia Farma Sario Manado Clinic. Samples were taken by purposive sampling technique that is as many as 70 people who meet the inclusion criteria. The research design used was a cross sectional study and data collected from respondents used a religiosity questionnaire and psychological well-being. The results of the Spearman Rho statistical test obtained a correlation coefficient of 0.570 (with a value of $p=0,000)$ which means the value of $p<\alpha(0.05)$. Conclution of this research hypothesis was accepted, this shows that there's a correlation between religiosity and psychological wellbeing in patients with diabetes mellitus at the Husada Kimia Farma Sario Manado Clinic.

Keywords : Religiosity, Psychological Well-Being, Diabetes Mellitus Patients
\end{abstract}

\begin{abstract}
Abstrak : Kesejahteraan Psikologis ialah sebuah pencapaian penuh dari potensi psikologis seseorang dan suatu keadaan ketika individu dapat menerima kekuatan dan kelemahan diri apa adanya, memiliki tujuan hidup, mengembangkan relasi yang positif dengan orang lain, menjadi pribadi yang mandiri, mampu mengendalikan lingkungan, dan terus bertumbuh secara personal. Tujuan penelitian ini adalah untuk mengetahui apakah ada hubungan religiusitas dengan kesejahteraan psikologis pada penderita diabetes mellitus di klinik husada kimia farma sario manado. Sampel diambil dengan teknik pengambilan purposive sampling yaitu sebanyak 70 orang yang memenuhi kriteria inklusi. Desain Penelitian yang digunakan adalah cross sectional study dan data dikumpulkan dari responden menggunakan kuesioner religiusitas dan kesejahteraan psikologis. Hasil Penelitian uji statistik Spearman Rho diperoleh koefisien korelasi sebesar 0,570 (dengan nilai $\mathrm{p}=0,000$ ) yang berarti nilai $p<\alpha(0,05)$. Kesimpulan bahwa hipotesis penelitian diterima, hal ini menunjukkan bahwa ada hubungan antara religiusitas dengan kesejahteraan psikologis pada pasien dengan diabetes mellitus di Klinik Husada Kimia Farma Sario Manado.
\end{abstract}

Kata Kunci : Religiusitas, Kesejahteraan Psikologis, Pasien Diabetes Mellitus 


\section{PENDAHULUAN}

Angka kejadian penyakit tidak menular semakin meningkat di masyarakat dan menjadi perhatian. Salah satu penyakit tidak menular (PTM) adalah Diabetes Melitus (DM). Diabetes Melitus (DM) merupakan kondisi yang ditandai oleh hiperglikemia akibat ketidakmampuan tubuh untuk menggunakan glukosa darah untuk energi. (American Diabetes Association, 2018). Jumlah penderita diabetes melitus di dunia mengalami peningkatan dari 108 juta orang pada tahun 1980 menjadi 422 juta orang pada tahun 2014. Prevalensi global dari diabetes melitus pada orang dewasa diatas usia 18 tahun mengalami peningkatan dari tahun 1980 sebesar $4,7 \%$ menjadi $8,5 \%$ pada tahun 2014. Berdasarkan jumlah tersebut negara Indonesia menempati urutan ke-5 terbesar di dunia (World Health Organization, 2018).

Laporan Badan Penelitian dan Pengembangan Kesehatan Kementrian Kesehatan dengan hasil Riset Kesehatan Dasar (RISKESDAS) tahun 2013 menyebutkan terjadi peningkatan prevalensi pada penderita diabetes melitus yang diperoleh berdasarkan wawancara, yaitu $1,1 \%$ pada tahun 2007 menjadi 1,5\% pada tahun 2013 sedangkan prevalensi diabetes melitus berdasarkan diagnosis dokter atau gejala pada tahun 2013 sebesar $2,1 \%$ dengan prevalensi terdiagnosis dokter tertinggi pada daerah Sulawesi Tengah $(3,7 \%)$ dan paling rendah pada daerah Jawa Barat $(0,5 \%)$, sedangkan prevalensi penderita diabetes di Sulawesi Utara mencapai 2,4\%. Kemudian menurut data RISKESDAS tahun 2018, terjadi peningkatan prevalensi pada penderita diabetes mellitus dari 6,9\% (tahun 2013) menjadi 8,5\% (2018).

Penyakit diabetes melitus ini dapat mengganggu kesehatan fisik dan psikis. Gangguan psikis berupa depresi, kecemasan, dan distress yang terjadi karena kecacatan fisik, kekhawatiran akan terjadinya komplikasi, khawatir makanan yang akan dimakan, dan menuntut seseorang untuk merubah gaya hidup yang sebelumnya. Hal ini akan mempengaruhi kesejahteran psikologis seseorang (Kartikasari, 2014).

Faktor - faktor yang mempengaruhi kesejahteraan psikologis yaitu berupa usia, jenis kelamin, budaya, tingkat pendidikan, locus of control, dukungan sosial, dan salah satu yang mempengaruhi kesejahteraan psikologis adalah religiusitas yang telah banyak dibahas dalam hubungannya dengan kesejahteraan psikologis. Individu dengan religiusitas yang tinggi, berkemungkinan lebih kecil mengalami depresi. Individu juga dapat merasa bahagia dalam menjalani kehidupan sehari - hari dan semakin sedikit dampak negatif yang dirasakan dari peristiwa traumatik dalam hidup (Papalia dkk, 2009). Agama dapat membangun keadaan positif, mengurangi stress, dan adanya kepercayaan terhadap Tuhan sebagai cara untuk menginterprestasikan kemalangan.

Religiusitas berfungsi sebagai pendukung kesembuhan seseorang. Pemenuhan kebutuhan religiusitas pada penderita diabetes mellitus dan dukungan dari keluarga membantu memperkuat dalam ketenangan jiwa. Religiusitas dalam psikologis seseorang sangat penting karena dari religiusitas dapat membangkitkan rasa percaya diri dan optimisme. Ibadah seperti berdoa sebagai permohonan dan harapan ke hadirat Tuhan Yang Maha Kuasa akan memberikan perasaan tenang. Ibadah yang dijalankan dapat mengurangi keadaan tidak menerima, rasa khawatir terjadinya komplikasi, khawatir tentang makanan yang akan dimakan yang mengakibatkan depresi, kecemasan dan stres. Menurut Taylor (2003) agama dapat mendukung keadaan psikologis seseorang dengan kepercayaan spiritual akan lebih memiliki kepuasan hidup dan kebahagiaan yang lebih besar dan trauma hidupnya lebih kecil dibanding orang yang tidak memiliki kepercayaan.

Data yang diperoleh di Klinik Husada Kimia Farma Manado, dari bulan Januari sampai dengan bulan Desember 2015 
penderita diabetes melitus mencapai 4330 pasien yang datang berkunjung dengan rata-rata kunjungan mencapai 360 pasien per bulan. Kemudian data terbaru di awal tahun 2018 pada bulan januari tercatat 414 kunjungan, bulan februari 375 kunjungan, dan pada bulan maret 380 kunjungan. Fenomena lain yang dijumpai oleh peneliti di lapangan, yaitu ada seorang penderita diabetes melitus yang berinisial MS, bapak MS hidup dengan istri dan kedua orang anaknya yang masing-masing telah menyelesaikan studi di perguruan tinggi ternama. Dalam menjalani kesehariannya, bapak MS menikmati masa pensiunnya dengan aktivitas yang melibatkan dirinya dengan lingkungan sekitar sehingga sakit yang diderita tidak sering kambuh. Bapak MS menyadari keadaan diri dan menerima dengan lapang. Beliau mengatakan selama ini rutin menjalankan ibadah sebagai bentuk rasa syukur kepada Tuhan atas segala hal yang telah terjadi dalam hidupnya, termasuk menderita diabetes mellitus selama 7 tahun. Hal yang dirasakan oleh bapak MS sesuai dengan penelitian Kartikasari (2014) yaitu spiritualitas menghubungkan dengan fungsi psikologis seseorang, keyakinan tentang akhirat, dan dapat meningkatkan keterhubungan dengan Tuhan yang dapat menurunkan tingkat stress pada penderita.

Berdasarkan hasil pemaparan diatas dapat disimpulkan bahwa perilaku beragama dapat mempengaruhi kesejahteraan psikologis seseorang. Dengan melaksanakan ibadah dengan rutin dan meyakininya dengan sepenuh hati akan membuat individu menjadi lebih baik dengan optimis, tegar, dan menerima kaeadaan diri. Semakin tinggi tingkat religiusitas semakin tinggi tingkat kesejahteraan psikologis dan membuat seseorang lebih bisa sembuh dari penyakit. Berdasarkan temuan awal tersebut penulis tertarik untuk meneliti masalah ini dengan judul penelitian "Hubungan religiusitas dengan kesejahteraan psikologis pada pasien diabetes melitus di Klinik Husada Kimia Farma Sario Manado".

\section{METODE PENELITIAN}

Bentuk penelitian yang dilakukan adalah penelitian survei analitik. Pendekatan yang digunakan adalah Cross Sectional Study, yaitu variabel sebab atau resiko dan akibat atau kasus yang terjadi pada objek penelitian diukur atau dikumpulkan secara simultan (point time approach) (Notoatmojo , 2010 ).

Penelitian ini dilaksanakan di Klinik Husada Kimia Farma Sario Manado. Penelitian telah dilaksanakan pada tanggal 12 November - 29 November 2018. Populasi dalam penelitian ini adalah pasien diabetes melitus yang sedang menjalani pengobatan di Klinik Husada Kimia Farma Sario Manado. Teknik pengambilan sampel dalam penelitian ini menggunakan non probability sampling yaitu purposive sampling, dimana pengambilan sampel yang didasarkan pada kehendak peneliti yang disesuaikan dengan tujuan serta kriteria yang sudah ditentukan (Setiadi, 2013). Jumlah sampel dalam penelitian ini yaitu 70 sampel. Instrumen yang digunakan adalah kuesioner religiusitas dan kuesioner kesejahteraan psikologis.

Kuesioner religiusitas terdiri dari 20 pertanyaan. Skala pengukuran menggunakan skala likert dengan pilihan jawaban : Sangat Setuju $=4$; Setuju $=3$; Tidak Setuju $=2$; Sangat Tidak Setuju 1 . Dengan kriteria penilaian baik jika skor $\geq$ 55 dan cukup jika skor $<55$. Kuesioner kesejahteraan psikologis terdiri dari 21 pertanyaan. Skala pengukuran menggunakan skala likert dengan pilihan jawaban : Sangat Setuju $=6$; Setuju $=5$; Agak Setuju $=4$; Agak Tidak Setuju $=$ $3 ;$ Tidak Setuju $=2 ;$ Sangat Tidak Setuju $=$ 1. Dengan kriteria penilaian baik jika skor $\geq 73,5$ dan cukup jika skor $<73,5$.

Data yang terkumpul diolah dan dianalisis dengan menggunakan program analisa data komputer (Kartikasari, 2014).

Tahapan dalam mendapatkan data yang benar dan mempermudah proses pengolahan data, dilakukan tahapan editing, coding, tabulating, cleaning. Analisis data dalam penelitian ini yaitu 
analisis univariat dan bivariat. Analisis univariat dilakukan terhadap setiap variabel independen dan variabel dependennya untuk mengetahui karakteristik penelitian dilakukan dengan menganalisis variabel variabel yang ada secara deskriptif dengan menghitung distribusi frekuensi dan proporsinya (Sugiyono, 2012). Analisis bivariat dilakukan untuk mengetahui adanya kemaknaan pengaruh antara variabel independen (religiusitas) dengan variabel dependen (kesejahteraan psikologis). Untuk membuktikan hipotesis penelitian, penulis menggunakan metode statistik, yaitu dengan teknik korelasi Spearman Rho dengan nilai $\alpha=0,05$. Signifikansi hubungan terlihat dari nilai $p$. Jika nilai $p<0,05$ maka dapat disimpulkan bahwa ada hubungan yang signifikan antara variabel independen dan dependen. Dalam melakukan penelitian, peneliti memperhatikan masalah - masalah etika penelitian yang meliputi : Informed Consent berisi pernyataan persetujuan sebagai subyek, yang diisi secara sukarela oleh subjek penelitian; Anonimity (Tanpa Nama) untuk menjaga privasi dan kerahasiaan subjek penelitian; dan Confidentiality menjaga informasi dan hasil penelitian dari orang yang tidak berhak mengakses kerahasiaan informasi responden (Nursalam, 2008).

HASIL dan PEMBAHASAN

Tabel 1. Distribusi Frekuensi Menurut Usia

Sumber : Data Primer, 2018

Jumlah responden pada tabel 1, yang paling banyak adalah responden yang berusia 6069 tahun yaitu 43 orang $(61,4 \%)$, responden yang memiliki usia termuda yaitu usia 3039 tahun berjumlah 1 orang $(1,4 \%)$, dan responden yang memiliki usia tertua adalah 70 tahun yaitu 4 orang $(5,7 \%)$.

Tabel 2. Distribusi Frekuensi Menurut Jenis Kelamin

\begin{tabular}{ccc}
\hline $\begin{array}{c}\text { Karakteristik } \\
\text { Jenis Kelamin }\end{array}$ & n & \% \\
\hline Laki-Laki & 24 & 34,3 \\
Perempuan & 46 & 65,7 \\
\hline Total & $\mathbf{7 0}$ & $\mathbf{1 0 0}$ \\
\hline
\end{tabular}

Sumber : Data Primer, 2018

Data yang dipaparkan pada tabel 2, dari 70 responden terdiri dari 24 laki-laki $(34,3 \%)$ dan 46 perempuan $(65,7 \%)$.

Tabel 3. Distribusi Frekuensi Menurut Agama

\begin{tabular}{ccc}
\hline $\begin{array}{c}\text { Karakteristik } \\
\text { Agama }\end{array}$ & n & $\%$ \\
\hline Islam & 6 & 8,6 \\
Kristen & 64 & 91,4 \\
\hline Total & $\mathbf{7 0}$ & $\mathbf{1 0 0}$ \\
\hline
\end{tabular}

Sumber : Data Primer, 2018

Data pada tabel 3, jumlah responden yang paling banyak yaitu beragama Kristen dengan jumlah 64 orang $(91,4 \%)$, dan sisanya beragama Islam dengan jumlah responden sebanyak 6 orang $(8,6 \%)$.

Tabel 4. Distribusi Frekuensi Menurut Pekerjaan

\begin{tabular}{ccc}
\hline $\begin{array}{c}\text { Karakteristik } \\
\text { Pekerjaan }\end{array}$ & n & \% \\
\hline IRT & 24 & 34,3 \\
Pensiunan & 43 & 61,4 \\
Pegawai Swasta & 1 & 1,4 \\
PNS & 1 & 1,4 \\
Dosen & 1 & 1,4 \\
\hline Total & $\mathbf{7 0}$ & $\mathbf{1 0 0}$ \\
\hline
\end{tabular}

Sumber : Data Primer, 2018

Jumlah responden pada tabel 4, yang paling banyak adalah responden dengan pekerjaan pensiunan yaitu 43 orang $(61,4 \%)$, responden yang memiliki pekerjaan sebagai ibu rumah tangga sebanyak 24 orang $(34,3 \%)$. Responden yang memiliki pekerjaan sebagai pegawai swasta 
berjumlah 1 orang $(1,4 \%)$, sama halnya dengan responden yang dengan pekerjaan sebagai pegawai negeri sipil yaitu 1 orang $(1,4 \%)$ dan dosen sebanyak 1 orang $(1,4 \%)$.

Tabel 5. Distribusi Frekuensi Menurut Lamanya Pasien Menderita Diabetes Mellitus

\begin{tabular}{ccc}
\hline $\begin{array}{c}\text { Karakteristik } \\
\text { Lama } \\
\text { Menderita DM }\end{array}$ & n & \% \\
\hline$<1$ tahun & 0 & 0 \\
$>1$ tahun & 70 & 100 \\
\hline Total & $\mathbf{7 0}$ & $\mathbf{1 0 0}$ \\
\hline
\end{tabular}

Sumber : Data Primer, 2018

Berdasarkan tabel 5, didapatkan data bahwa dari 70 responden yang diteliti, semuanya menderita diabetes mellitus lebih dari 1 tahun.

Tabel 6. Distribusi Frekuensi Menurut Tingkat Religiusitas

\begin{tabular}{ccc}
\hline $\begin{array}{c}\text { Tingkat } \\
\text { Religiusitas }\end{array}$ & n & \% \\
\hline Baik & 68 & 97,1 \\
Cukup & 2 & 2,9 \\
\hline Total & $\mathbf{7 0}$ & $\mathbf{1 0 0}$ \\
\hline
\end{tabular}

Sumber : Data Primer, 2018

Data dari hasil kuesioner dalam tabel 6, terlihat bahwa responden terbanyak adalah yang memiliki tingkat religiusitas baik yaitu sebanyak 68 orang $(97,1 \%)$. Sedangkan yang memiliki tingkat religiusitas cukup ada 2 orang $(2,9 \%)$.

Tabel 7. Distribusi Frekuensi Menurut Tingkat Kesejahteraan Psikologis

\begin{tabular}{ccc}
\hline $\begin{array}{c}\text { Tingkat } \\
\begin{array}{c}\text { Kesejahteraan } \\
\text { Psikologis }\end{array}\end{array}$ & n & \% \\
\hline Baik & 68 & 97,1 \\
Cukup & 2 & 2,9 \\
\hline Total & $\mathbf{7 0}$ & $\mathbf{1 0 0}$ \\
\hline
\end{tabular}

Sumber : Data Primer, 2018

Berdasarkan data yang dipaparkan pada tabel 7, didapatkan bahwa dari hasil kuesioner dalam penelitian ini responden terbanyak adalah yang memiliki tingkat kesejahteraan psikologis baik yaitu sebanyak 68 orang $(97,1 \%)$. Sedangkan yang memiliki tingkat religiusitas cukup ada 2 orang $(2,9 \%)$.

Tabel 8. Hubungan Religiusitas dengan Kesejahteraan Psikologis pada Pasien Diabetes Mellitus di Klinik Husada Kimia Farma Manado

\begin{tabular}{|c|c|c|c|c|c|c|c|c|}
\hline \multirow{3}{*}{$\begin{array}{l}\text { Tingkat } \\
\text { Religiusitas }\end{array}$} & \multicolumn{4}{|c|}{$\begin{array}{c}\text { Kesejahtraan } \\
\text { psikologis }\end{array}$} & \multirow{2}{*}{\multicolumn{2}{|c|}{ Total }} & \multirow{3}{*}{$\mathbf{r}$} & \multirow{3}{*}{$\begin{array}{c}\text { Nilai } \\
p\end{array}$} \\
\hline & \multicolumn{2}{|c|}{ Cukup } & \multicolumn{2}{|c|}{ Baik } & & & & \\
\hline & $\mathbf{n}$ & $\%$ & n & $\%$ & $\mathbf{n}$ & $\%$ & & \\
\hline Cukup & 0 & 0 & 2 & 2,9 & 2 & 2,9 & \multirow{2}{*}{0,570} & \multirow{2}{*}{0,000} \\
\hline Baik & 2 & 2,9 & 66 & 94,3 & 68 & 97,1 & & \\
\hline Total & 2 & 2,9 & 68 & 97,1 & 70 & 100 & & \\
\hline
\end{tabular}

Sumber : Data Primer, 2018

Tabel 8 di atas menunjukkan bahwa hasil uji korelasi dengan menggunakan Spearman Rho menunjukkan nilai $\mathrm{r}$ hitung sebesar 0,570 , dan memperlihatkan nilai $p$ yang didapat adalah sebesar 0,000 , yang berarti lebih kecil dari nilai $\alpha=0,05$. Hal ini memberikan arti bahwa $\mathrm{H}_{\mathrm{a}}$ diterima dan $\mathrm{H}_{\mathrm{o}}$ ditolak, yang berarti ada hubungan antara religiusitas dengan kesejahteraan psikologis pasien diabetes mellitus. Hal tersebut menunjukkan bahwa ada hubungan positif antara religiusitas dengan kesejahteraan psikologis. Semakin tinggi religiusitas semakin tinggi juga kesejahteraan psikologis seseorang.

\section{Karakteristik Responden}

Berdasarkan hasil penelitian yang dilakukan menunjukkan bahwa sebagian besar responden yang menjadi pasien di Klinik Husada Kimia Farma Manado berusia 60-69 tahun (61,4\%). Menurut Rajawane (2011), usia 60-69 tahun termasuk dalam kategori Young Old yang berarti orang pada tahap usia ini didihadapkan pada masalah berkurangnya peran, aktivitas, teman dan penghasilan sebagai konsekuensi dari masa pensiun yang baru dimasukinya. Penurunan kondisi ini tidak dapat dihindari namun bila sebelumnya cara hidupnya cukup baik, maka pada masa ini pada umumnya lanjut usia masih memiliki kekuatan untuk 
melakukan kegiatan fisik, untuk menggantikan pekerjaan sebelum pensiun dan juga menghasilkan uang.

Penelitian yang dilakukan pada 70 responden menunjukkan bahwa responden terbanyak adalah perempuan dengan jumlah sebanyak 46 orang $(65,7 \%)$ dan 24 laki-laki (34,3\%). Hasil tersebut didukung dengan data dari Riset Kesehatan Dasar (RISKESDAS) pada tahun 2013 yang mengatakan bahwa angka kenaikan DM lebih tinggi pada perempuan yaitu sebesar $7,7 \%$ sedangkan laki-laki 5,6\%, dari nasional $6,9 \%$. Hal ini disebabkan oleh peningkatan angka obesitas pada perempuan yang cenderung lebih tinggi disbanding laki-laki. Perempuan meningkat dari 14,8\% (2007) menjadi 32,9\% (2013), sedangkan laki-laki hanya $13,9 \%$ menjadi $19,7 \%$.

Responden yang paling banyak yaitu beragama Kristen dengan jumlah 64 orang $(91,4 \%)$, dan sisanya beragama Islam dengan jumlah responden sebanyak 6 orang $(8,6 \%)$. Hal ini didukung dengan hasil survei Badan Pusat Statistik Sulawesi Utara pada tahun 2015 bahwa jumlah penganut agama Kristen mencapai 1,7 juta penduduk (61,45\%). Lalu agama Islam 797 ribu penduduk $(31,65 \%)$, Katolik 167 ribu (5,81\%), Hindu 26 ribu (0,93\%), Budha 24 ribu $(0,11 \%)$, dan Khonghucu $718(0,05 \%)$.

Jumlah responden yang paling banyak adalah responden pensiunan yaitu 43 orang $(61,4 \%)$, responden yang memiliki pekerjaan sebagai ibu rumah tangga sebanyak 24 orang $(34,3 \%)$, responden yang memiliki pekerjaan sebagai pegawai berjumlah 1 orang $(1,4 \%)$, sama halnya dengan responden yang dengan pekerjaan sebagai pegawai negeri sipil dan dosen masing-masing berjumlah 1 orang $(1,4 \%)$. Hal ini berkaitan dengan data karakteristik usia responden yang masuk pada kategori usia young old. Menurut Rajawane (2011), penduduk yang digolongkan lanjut usia adalah yang berusia 60 tahun ke atas dan dianggap sudah kurang atau tidak produktif lagi. Dalam pengertian kemampuannya untuk menghasilkan sesuatu yang berbentuk materi atau benda berkurang atau tidak ada sama sekali. Orang-orang yang dianggap telah lanjut usia, dengan kondisi fisik dan psikis yang telah menurun kemampuannya.

Hasil penelitian ini ditemukan adanya hubungan religiusitas dengan kesejahteraan psikologis pada pasien diabetes mellitus di klinik husada kimia farma sario manado. Ini bisa dilihat melalui uji Spearman Rho dengan tingkat kemaknaan $95 \%(\alpha=0,05)$, hasil analisa yaitu 0,000 , maka nilai $p<\alpha$ (tabel 8). Sebanyak 68 orang dari 70 total responden memiliki tingkat religiusitas dan kesejahteraan psikologis yang baik, sedangkan 2 sisanya memiliki tingkat religiusitas dan kesejahteraan psikologis yang cukup. Hal ini sejalan dengan penelitian yang dilakukan oleh Rajawane (2011) Hubungan Religiusitas dengan Kesejahteraan Psikologi pada Lanjut Usia memunculkan hasil analisa data dengan koefisien korelasi sebesar 0,694 (dengan nilai $\mathrm{p}=0,000$ ) yang terdapat hubungan yang positif antara Religiusitas dengan Kesejahteraan Psikologis pada lanjut usia. Serta penelitian yang dilakukan oleh Kartikasari (2014), Hubungan Religiusitas dengan Kesejahteraan Psikologis pada Pasien DM tipe 2 di RSUD Moewardi Surakarta dengan hasil korelasi positif antara tingkat religiusitas dan kesejahteraan psikologis.

Pembahasan mengenai gambaran tingkat religiusitas dan tingkat kesejahteraan psikologis pada masingmasing sub bab, didapatkan hasil yang sama, yakni tingkat religiusitas yang baik adalah 68 orang $(97,1 \%)$, begitu pula jumlah responden dengan tingkat kesejahteraan psikologis yang baik. Kemudian jumlah responden yang memiliki tingkat religiusitas cukup berjumlah 2 orang (2,9\%), hasil ini sama dengan jumlah responden dengan tingkat kesejahteraan psikologis yang cukup. Akan tetapi 2 orang yang mewakili tingkat religiusitas yang cukup adalah 2 orang berbeda yang mewakili tingkat kesejahteraan psikologis yang cukup. 
Berdasarkan penelitian ini, diperoleh hasil sebagian besar pasien mempunyai tingkat religiusitas yang baik, didapatkan hasil tingkat kesejahteraan psikologis pasien juga baik. Adapun faktor yang diperoleh oleh peneliti bahwa tingkat kesejahteraan psikologis yang baik dipengaruhi oleh faktor demografis, dukungan sosial, religiusitas, dan kepribadian.

Melihat uraian diatas, sebagian besar pasien diabetes yang berada di Klinik Husada Kimia Farma Sario Manado dapat mengatasi masalah yang ia hadapi dalam menjalani hari dan menerima keadaan mereka sebagai penderita diabetes mellitus adalah mencapai kesejahteraan psikologis karena dengan mencapai kesejahteraan psikologis maka dapat membantu para pasien DM keluar dari masalah-masalah yang berpotensial muncul. Beberapa cara yang dapat dilakukan untuk mencapai kesejahteraan psikologis pada pasien DM adalah dengan menjalin hubungan (jejaring) yang baik dengan orang-orang di sekitar lingkungan dan berusaha untuk terlibat aktif dalam berbagai kegiatan yang ada seperti bidang keagamaan sebagai salah satu cara untuk mendapatkan kesejahteraan psikologis menurut Ryff (Synder \& Lopez, 2007).

\section{SIMPULAN}

1. Tingkat religiusitas pada pasien diabetes mellitus di Klinik Husada Kimia Farma Sario Manado adalah baik

2. Responden terbanyak adalah responden dengan tingkat kesejahteraan psikologis baik

3. Ada hubungan antara religiusitas dan kesejahteraan psikologis pada pasien diabetes mellitus di Klinik Husada Kimia Farma Manado

\section{DAFTAR PUSTAKA}

American Diabetes Association Standards of Care. (2018). https://diabetesed.net/wpcontent/uploads/2017/12/2018ADA-Standards-of-Care.pdf.
Badan Penelitian dan Pengembangan Kesehatan, Riset Kesehatan Dasar 2013; Laporan Nasional 2013

Badan Penelitian dan Pengembangan Kesehatan, Riset Kesehatan Dasar 2018; Laporan Nasional 2018

Badan Pusat Statistik. (2015). https://www.bps.go.id/istilah/index .html?istilah_sort=keyword....

Kartikasari, N. D. (2014). Hubungan Religiusitas dengan Kesejahteraan Psikologis pada Penderita Diabetes Mellitus Tipe 2. Jurnal Psikologi Universitas Muhammadiyah Surakarta. http://eprints.ums.ac.id/31986/1/02. $\% 20$ Naskah\%20Publikasi.pdf.

Notoatmodjo, S. (2010). Metodologi Penelitian Kesehatan. Jakarta: Rineka Cipta

Nursalam, P.S. (2008). Pendekatan Praktis Metodologi Riset Keperawatan. CV. Agung Ceto: Jakarta

Papalia D.E., Olds, S.W, \& Feldman, R.D. (2009). Human Development (Perkembangan Manusia edisi 10 buku 2). (Penerj. Brian Marwensdy). Jakarta: Salemba Humanika.

Rajawane, I. (2011). Hubungan Religiusitas dengan Kesejahteraan Psikologis pada Lansia. Jurnal Universitas Islam Negeri Sultan Syarif Kasim Riau. http://repository.uinsuska.ac.id/1188/

Setiadi. (2013). Konsep Dan Praktik Penulisan Riset Keperawatan. Edisi 2. Yogyakarta : Graha Ilmu 
e-journal Keperawatan (e-Kp) Volume 7 Nomor 1, 17 Februari 2019

Sugiyono. (2012). Metode Penelitian Kuantitatif, Kualitatif, Dan $R \& D$. Bandung : Alfabeta

Snyder, C.R., \& Lopez, S.J. (2007). Handbook Of Positive Psychology. Google Books .https://www.slideshare.net/koccint osbor9/snyder-c-r-lopez-s-j-edshandbook-of-positive-psychology

Taylor, S,E. (2003). Health Psychology, Los Angeles : University of California

World Health Organization. (2018). (https://www.who.int/mediacentre/ factsheets/fs138/en/) 